\title{
Erythropoietin Is a Paracrine Mediator of Ischemic Tolerance in the Brain: Evidence from an In Vitro Model
}

\author{
Karsten Ruscher, ${ }^{1}$ Dorette Freyer, ${ }^{1}$ Maria Karsch, ${ }^{1}$ Nikolai Isaev, ${ }^{3}$ Dirk Megow, ${ }^{1}$ Birgit Sawitzki, ${ }^{2}$ \\ Josef Priller, ${ }^{1}$ Ulrich Dirnagl, ${ }^{1}$ and Andreas Meisel ${ }^{1}$ \\ Departments of ${ }^{1}$ Experimental Neurology and Neurology and ${ }^{2}$ Medical Immunology, Charité Hospital, Humboldt \\ University, D-10098 Berlin, Germany, and ${ }^{3}$ A. N. Belozersky Institute of Physico-Chemical Biology, Moscow State \\ University, 119899 Moscow, Russia
}

In an in vitro model of cerebral ischemia (oxygen glucose deprivation, OGD) we investigated whether erythropoietin (EPO) plays a critical role in ischemic preconditioning. We found that EPO time and dose-dependently induced protection against OGD in rat primary cortical neurons. Protection was significant at $5 \mathrm{~min}$ and reached a maximum at $48 \mathrm{hr}$ after EPO application. Protection was blocked by the coapplication of a soluble Epo receptor (sEpoR) or an antibody against EpoR (anti-EpoR). Medium transfer from OGD-treated astrocytes to untreated neurons induced protection against OGD in neurons, which was attenuated strongly by the application of sEpoR and anti-EpoR. In contrast, medium transfer from OGD-treated neurons to untreated neurons induced protection against OGD that did not involve EPO. In astrocytes the OGD enhanced the nuclear translocation of hypoxia-inducible factor 1 (HIF-1), the major transcription factor regulating EPO expression. Consequently, transcription of EPO-mRNA was increased in astrocytes after OGD. Cultured neurons express EpoR, and the

In the brain a nonlethal ischemic event can induce tolerance against subsequent, more severe ischemia: "ischemic preconditioning" (IP) or "ischemic tolerance" (Kitagawa et al., 1990). IP is a biphasic phenomenon, with an early short-lasting phase of protection that develops within minutes from the initial ischemic insult and lasts $\sim 2 \mathrm{hr}$. Subsequently, a cascade of signaling events initiated by the preconditioning stress establishes delayed protection. This delayed phase becomes apparent 12-72 $\mathrm{hr}$ after the preconditioning event and lasts for at least $3 \mathrm{~d}$ (Perez-Pinzon et al., 1997). Because of its sustained duration and potential clinical relevance (Weih et al., 1999; Moncayo et al., 2000), considerable interest recently has been focused on the delayed phase of IP.

To elucidate the mechanisms of IP, we and others have modeled IP in vitro. At $24-78 \mathrm{hr}$ after murine or rat cortical cell cultures were exposed to sublethal oxygen glucose deprivation (OGD), reduced neuronal death to otherwise lethal OGD was observed (Bruer et al., 1997; Grabb and Choi, 1999; GonzalezZulueta et al., 2000). There is evidence that OGD preconditioning is NMDA receptor-dependent (Grabb and Choi, 1999) and

Received Dec. 6, 2001; revised Sept. 3, 2002; accepted Sept. 24, 2002.

This work was supported by the Hermann and Lilly Schilling Foundation and the Deutsche Forschungsgemeinschaft. We thank Claudia Muselmann and Renate Gusinda for excellent technical assistance.

Correspondence should be addressed to Dr. Andreas Meisel, Department of Neurology, Charité Hospital, Humboldt University, Schumannstrasse 20-21, D-10098 Berlin, Germany. E-mail: andreas.meisel@charite.de.

Copyright (C) 2002 Society for Neuroscience 0270-6474/02/2210291-11\$15.00/0
Janus kinase-2 (JAK-2) inhibitor AG490 abolished EPOinduced tolerance against OGD. Furthermore, EPO-induced neuroprotection as well as phosphorylation of the proapoptotic Bcl family member Bad was reduced by the phosphoinositide-3 kinase (PI3K) inhibitor LY294002. The results suggest that astrocytes challenged with OGD provide paracrine protective signals to neurons. We provide evidence for the following signaling cascade: HIF-1 is activated rapidly by hypoxia in astrocytes. After HIF-1 activation the astrocytes express and release EPO. EPO activates the neuronal EPO receptor and, subsequently, JAK-2 and thereby PI3K. PI3K deactivates BAD via Aktmediated phosphorylation and thus may inhibit hypoxiainduced apoptosis in neurons. Our results establish EPO as an important paracrine neuroprotective mediator of ischemic preconditioning.

Key words: astrocyte; Bad; hypoxia-inducible factor-1; ischemic preconditioning; Janus kinase-2; neuron; oxygen glucose deprivation; phosphoinositol-3 kinase

that induction of Ras in an NMDA- and NO-dependent manner is sufficient and necessary for tolerance induction in vitro (Gonzalez-Zulueta et al., 2000). Furthermore, the initial signals for triggering preconditioning involve the opening of ATPsensitive $\mathrm{K}^{+}$channels via the activation of adenosine $\mathrm{A}_{1}$ receptors (Heurteaux et al., 1995; Plamondon et al., 1999). Although most of IP research has focused on intracellular mechanisms, intercellular communication as a route of protective signaling has, in large part, been overlooked. In particular, glial cells, besides participating in the extracellular homeostasis of ions and metabolites in the brain (Ridet et al., 1997), are well known to produce a host of trophic and protective proteins after various stimuli, raising the issue of glial-neuronal protective signaling in IP.

Astrocytes are the main cellular source of the glycoprotein hormone erythropoietin (EPO) in the brain, and low oxygen tension stimulates EPO-mRNA expression in astrocytes. EPO receptor (EpoR) has been detected in neurons as well as in astrocytes (Masuda et al., 1993, 1994; Digicaylioglu et al., 1995; Marti et al., 1996; Liu et al., 1997; Juul et al., 1998; Bernaudin et al., 2000). This may have implications for IP, because EPO has potent neuroprotective properties in vivo and in vitro (Konishi et al., 1993; Morishita et al., 1997; Sadamoto et al., 1998; Sakanaka et al., 1998; Bernaudin et al., 1999; Brines et al., 2000; Calapai et al., 2000; Sinor and Greenberg, 2000; Sirén et al., 2001). EPOinduced neuroprotection seems to be mediated mainly by antiapoptotic signaling cascades, which are well established for the 
role of EPO in hematopoiesis (Socolovsky et al., 1999; Lawson et al., 2000). The expression of EPO is regulated by the transcription factor hypoxia-inducible factor-1 (HIF-1) (Semenza, 2000). Recent studies suggest that HIF-1 mediates hypoxia-induced preconditioning in the brain (Ruscher et al., 1998; Zaman et al., 1999; Bergeron et al., 2000), indirectly suggesting a role for EPO in IP.

To address protective astroglial-neuronal signaling and a putative role of EPO herein, we have used purified cell cultures of astrocytes and neurons, because in these systems it is straightforward to separate and identify soluble extracellular factors from intracellular mechanisms by transferring conditioned medium from one cell type or stimulus condition to another. We tested the following hypotheses: (1) hypoxia in astrocytes induces HIF-1, which transactivates EPO synthesis; (2) EPO released into the extracellular space acts as a paracrine endogenous neuroprotectant; and (3) neuroprotection occurs via a cascade of protein phosphorylation that counteracts hypoxia-induced apoptosis.

\section{MATERIALS AND METHODS}

Cell cultures. All media and supplements were purchased from Biochrom (Berlin, Germany) unless otherwise noted. Primary neuronal cultures of cerebral cortex were obtained from embryos (E16-E18) of Wistar rats (Bundesinstitut für gesundheitlichen Verbraucherschutz und Veterinärmedizin, Berlin, Germany). Cultures were prepared according to Brewer (1995), with the following modifications: cerebral cortex was dissected, meninges were removed, and tissue was incubated for $15 \mathrm{~min}$ in trypsin/ $\operatorname{EDTA}(0.05 / 0.02 \% \mathrm{w} / \mathrm{v}$ in $\mathrm{PBS})$ at $37^{\circ} \mathrm{C}$; the cultures were rinsed twice with PBS and once with dissociation medium (modified Eagle's medium with $10 \%$ fetal calf serum, $10 \mathrm{~mm}$ HEPES, $44 \mathrm{~mm}$ glucose, $100 \mathrm{U}$ penicillin plus streptomycin/ml, $2 \mathrm{~mm}$ L-glutamine, $100 \mathrm{IE}$ insulin/l), dissociated by Pasteur pipette in dissociation medium, pelleted by centrifugation $\left(210 \times g\right.$ for $2 \mathrm{~min}$ at $\left.21^{\circ} \mathrm{C}\right)$, redissociated in starter medium [Neurobasal medium with supplemental B27 (Invitrogen, Paisley, UK), $100 \mathrm{U}$ penicillin + streptomycin $/ \mathrm{ml}, 0.5 \mathrm{mM}$ L-glutamine, $25 \mu \mathrm{M}$ glutamate], and plated in 24-well plates or six-well plates in a density of 200,000 cells $/ \mathrm{cm}^{2}$. Wells were pretreated by incubation with poly-L-lysine $(0.5 \% \mathrm{w} / \mathrm{v}$ in PBS) for $1 \mathrm{hr}$ at room temperature and then rinsed with PBS, followed by incubation with coating medium (dissociation medium with $0.03 \mathrm{w} / \mathrm{v}$ collagen $\mathrm{G}$ ) for $1 \mathrm{hr}$ at $37^{\circ} \mathrm{C}$; then they were rinsed twice with PBS before the cells were seeded in starter medium. Cultures were kept at $36.5^{\circ} \mathrm{C}$ and $5 \% \mathrm{CO}_{2}$ and fed beginning from $4 \mathrm{~d}$ in vitro (DIV) with cultivating medium (starter medium without glutamate) by replacing one-half of the medium twice a week. The cultures were used for experiments after $8 \mathrm{DIV}$, containing $<10 \%$ astroglial cells.

Astroglial cell cultures were prepared according to a modified method described by McCarthy and de Vellis (1980). In brief, meninges from cortices of newborn Wistar rats were removed, and the tissue was dissected mechanically and digested in trypsin/EDTA solution $(0.05 \%$ Trypsin, $0.02 \%$ EDTA) at $37^{\circ} \mathrm{C}$ for $15 \mathrm{~min}$. After digestion the tissue was washed two times in PBS, followed by a mechanical dissociation in DMEM with a pipette. The dissociated cells were seeded in $75 \mathrm{~cm}^{2}$ flasks (2 brains/flask). Cells were grown in DMEM (10\% FCS, $1 \%$ penicillin/ streptomycin, $2 \mathrm{~mm}$ L-glutamine, $0.1 \%$ glucose). After $8-10 \mathrm{~d}$ the cultures were shaken for $2 \mathrm{hr}$ at $200 \mathrm{rpm}$ to remove microglial cells, and astrocytes were reseeded in subcultures.

Induction of neuroprotection by OGD-conditioned medium from astrocytes. Experiments were performed with confluent astrocytes grown in the second subculture. For adaptation of the astrocytes, $72 \mathrm{hr}$ before OGD the astroglial medium (DMEM) was exchanged by neuronal medium (NBM supplemented with B27), as shown in Figure 5A. For astrocyte OGD the culture medium was washed out with PBS, and OGD was induced with a deoxygenated aglycemic solution [DAS; containing (in $\mathrm{mM}$ ) $143.8 \mathrm{Na}^{+}, 5.5 \mathrm{~K}^{+}, 1.8 \mathrm{Ca}^{2+}, 1.8 \mathrm{Mg}^{2+}, 125.3 \mathrm{Cl}^{-}, 26.2$ $\mathrm{HCO}_{3}{ }^{-}, 1.0 \mathrm{PO}_{4}{ }^{3-}$, and $\left.0.8 \mathrm{SO}_{4}{ }^{2-}, \mathrm{pH} 7.4\right]$ in a hypoxic atmosphere (1\% oxygen). Hypoxia was generated in a dedicated, humidified gas-tight incubator (Concept 400, Ruskinn Technologies, Bridgend, UK) and flushed with gas of the following composition: $5 \% \mathrm{CO}_{2}, 85 \% \mathrm{~N}_{2}$, and $10 \% \mathrm{H}_{2}$. During OGD (180 min) oxygen tensions in the media were below $1 \mathrm{mmHg}$ (polarographic probe, Licox GSM). In control experiments the medium was replaced by basic salt solution [BSS; containing (in mM) $143.8 \mathrm{Na}^{+}, 5.5 \mathrm{~K}^{+}, 1.8 \mathrm{Ca}^{2+}, 1.8 \mathrm{Mg}^{2+}, 125.3 \mathrm{Cl}^{-}, 26.2$ $\mathrm{HCO}_{3}{ }^{-}, 1.0 \mathrm{PO}_{4}{ }^{3-}$, and $0.8 \mathrm{SO}_{4}{ }^{2-}$ plus $4.5 \mathrm{gm} / 1$ glucose, $\left.\mathrm{pH} 7.4\right]$ after being washed with $\mathrm{PBS}$, and cells were incubated in a normoxic atmosphere containing $5 \% \mathrm{CO}_{2}$ (see Fig. $5 \mathrm{~A}$ ). Immediately after OGD preconditioning of astrocytes the solutions were replaced by fresh NBM supplemented with B27. Then $24 \mathrm{hr}$ later the medium was removed from astrocytes $\left(25 \mathrm{ml} / 2 \times 10^{6}\right.$ cells); subsequently, neuronal cultures (8 DIV) were fed with the preconditioned medium $(400 \mu \mathrm{l})$ for $48 \mathrm{hr}$. In parallel experiments, $2.5 \mu \mathrm{g} / \mathrm{ml}$ antibody against erythropoietin receptor (antiEpoR) or $2.5 \mu \mathrm{g} / \mathrm{ml}$ soluble EpoR was added to the astrocyte preconditioned medium before being added to neuronal cultures (see Fig. $5 A$ ). For neuronal OGD, immediately before starting OGD the medium was removed and washed out with PBS. Medium from untreated cells was stored at $37^{\circ} \mathrm{C}$. Thereafter, OGD was induced with DAS medium in a hypoxic atmosphere. Hypoxia was generated as described above. In control experiments the medium was replaced by BSS (after washing with PBS), and the cells were incubated in a normoxic atmosphere containing $5 \% \mathrm{CO}_{2}$. Immediately after OGD the hypoxic or basic salt solution was replaced by $25 \%$ of stored medium and $75 \%$ fresh NBM supplemented with B27. After $24 \mathrm{hr}$ lactate dehydrogenase (LDH) activities were measured in the medium supernatant as a marker of cell death (see Fig. $5 A$ ).

Induction of neuroprotection by $O G D$-conditioned medium from primary cortical neurons. Experiments were performed with rat primary cortical neurons cultured for 8 DIV. For OGD preconditioning the culture medium was washed out with PBS, and OGD was induced with DAS medium in a hypoxic atmosphere (see Fig. $6 A$ ). Hypoxia was generated as described in the astrocyte preconditioning protocol. In control experiments the medium was replaced by BSS (after being washed with PBS), and the cells were incubated in a normoxic atmosphere containing 5\% $\mathrm{CO}_{2}$ (see Fig. $6 \mathrm{~A}$ ). Immediately after OGD preconditioning of neurons the solutions were replaced by fresh NBM supplemented with B27. Then $24 \mathrm{hr}$ later the medium was removed from neurons $\left(30 \mathrm{ml} / 18 \times 10^{6}\right.$ cells); subsequently, fresh neuronal cultures (8 DIV) were fed with the preconditioned medium $(400 \mu \mathrm{l})$ for $48 \mathrm{hr}$. In parallel experiments, $2.5 \mu \mathrm{g} / \mathrm{ml}$ anti-EpoR antibody or $2.5 \mu \mathrm{g} / \mathrm{ml}$ soluble erythropoietin receptor (sEpoR) was added to the neuron preconditioned medium before being added to fresh neuronal cultures (see Fig. 6A). For lethal OGD, immediately before OGD was started, the medium was removed and washed out with PBS. Medium from untreated cells was stored at $37^{\circ} \mathrm{C}$. Neurons were OGD-treated as described in the astrocyte-preconditioning protocol. After $24 \mathrm{hr}$ LDH activities were measured in the medium supernatant as a marker of cell death (see Fig. 6A).

Recombinant human EPO stimulation of neurons. For pretreatment with EPO, cultured neurons (8 DIV) were incubated in the plating medium containing recombinant human EPO (rhEPO) at final concentrations of 1, 10, or $100 \mathrm{U} / 1$, respectively (Sigma-Aldrich, Deisenhofen, Germany), under normoxic, humidified conditions. At different time points (as indicated in the figures) the culture medium was removed and washed out with PBS to nondetectable levels (data not shown) as measured by an erythropoietin chemiluminescent immunoassay. Medium from untreated cells was stored at $37^{\circ} \mathrm{C}$. Neurons were OGD-treated as described in the astrocyte preconditioning protocol. Immediately after OGD the hypoxic or basic salt solution was replaced by $25 \%$ of stored medium and $75 \%$ fresh NBM supplemented with B27. For post-OGD incubation with EPO the cultured neurons (8 DIV) were OGD-treated for $120 \mathrm{~min}$ as described in the astrocyte preconditioning protocol. Immediately after OGD, $100 \mathrm{U} / 1 \mathrm{EPO}$ (final concentration) was added to the replaced medium (25\% of stored medium and $75 \%$ fresh NBM supplemented with B27). After $24 \mathrm{hr}$ LDH activities were measured in the medium supernatant. In parallel experiments, $2.5 \mu \mathrm{g} / \mathrm{ml}$ anti-EpoR or $2.5 \mu \mathrm{g} / \mathrm{ml} \mathrm{sEpoR}$ was coapplied with $100 \mathrm{U} / 1 \mathrm{rhEPO}$ to the neuronal culture medium and washed out with the NBM culture medium immediately before OGD. The kinase inhibitors LY294002 and AG490 were obtained from Promega (Mannheim, Germany) and Calbiochem (Schwalbach, Germany), respectively.

Erythropoietin chemiluminescent immunoassay. EPO concentrations were measured by the EPO Immulite assay according the manufacturer's instructions (DPC Biermann, Bad Nauheim, Germany).

Lactate dehydrogenase assay. At $24 \mathrm{hr}$ after OGD or BSS stimulation cell injury was assessed by using phase-contrast microscopy and by measurement of LDH activity. In neuronal cultures the LDH activity in the medium robustly correlated with the number of damaged cells (Koh and Choi, 1987). LDH release was measured as described previously (Bruer et al., 1997). 
Ethidium bromide and acridine orange staining. The fluorescent DNAbinding dyes ethidium bromide and acridine orange were used to confirm apoptosis, by visualization of condensed and fragmented chromatin, and to distinguish necrotic from apoptotic cells. Whereas acridine orange is membrane-permeable and stains living cells, ethidium homodimer cannot penetrate intact cellular membranes and stains the nucleus of cells with a disrupted membrane. Therefore, stained cells with a regular-sized green fluorescent nucleus represents living cells. Early apoptotic cells have a green fluorescent condensed, shrunken, or fragmented nucleus; late apoptotic cells have a red fluorescent condensed, shrunken, or fragmented nucleus. Necrotic cells exhibit a red fluorescent regular-sized or increased nucleus. After treatment as indicated, primary cortical neurons were incubated in $2 \mu \mathrm{g} / \mathrm{ml} \mathrm{AO} \mathrm{(Sigma-Aldrich)} \mathrm{and} 2 \mu \mathrm{g} / \mathrm{ml} \mathrm{EB}$ (Sigma-Aldrich) for $5 \mathrm{~min}$ before imaging and cell counting, using a fluorescence microscope with a standard fluorescein excitation filter (Leica, Heerbrueg, Switzerland).

Terminal deoxynucleotidyl transferase-mediated biotinylated UTP nick end labeling assay. For terminal deoxynucleotidyl transferase-mediated biotinylated UTP nick end labeling (TUNEL) assay, the cells were air-dried and fixed with freshly prepared fixation solution (4\% PFA in PBS, pH 7.4). TUNEL was performed by using a fluorescence in situ Cell Death Detection Kit (Roche, Mannheim, Germany) according to the manufacturer's instructions.

DNA laddering. DNA was extracted by using a modified commercial Easy-DNA Kit (Invitrogen BV, Breda, Netherlands). DNA (2 $\mu \mathrm{g}$ ) was separated on a $2 \%$ agarose gel and stained by ethidium bromide. DNA fragments were analyzed with a fluorescence imager (Typhoon, Amersham Biosciences, Freiburg, Germany).

Immunocytochemistry. For immunocytochemical analysis the neurons were plated on glass coverslips and fixed with $4 \%$ paraformaldehyde for 10 min. After pretreatment in PBS supplemented with $0.3 \%$ Triton $\mathrm{X}-100$ and $10 \%$ normal goat serum, the coverslips were incubated overnight with a polyclonal antibody against EpoR (Santa Cruz Biotechnology, Freiburg, Germany) at a dilution of 1:100. After several washes a secondary biotinylated goat anti-rabbit antibody (Vector Laboratories, Burlingame, CA) was applied at a dilution of 1:200 for $30 \mathrm{~min}$. Visualization was achieved via the Vectorstain ABC Elite kit (Vector Laboratories) reacted with 3,3'-diaminobenzidine $/ \mathrm{H}_{2} \mathrm{O}_{2}$ (Sigma-Aldrich). Omission of the primary antibody served as a negative control.

Fluorescent electrophoretic mobility shift assay. Nuclear extracts were prepared as described previously (Ruscher et al., 2000). For gel shift assays 1 pmol of Cy5-labeled specific probe was incubated with $25 \mu \mathrm{g}$ of protein of nuclear extracts in binding buffer BBN [containing (in $\mathrm{mM}$ ) 20 HEPES, $50 \mathrm{KCl}, 1$ EDTA, and 1 DTT plus $25 \mathrm{ng}$ poly(dI)·poly(dC), $10 \%$ glycerol] for $15 \mathrm{~min}$ at room temperature. The following Cy5-labeled specific double-stranded probes were used for HIF-1 and signal transducer and activator of transcription (STAT1), STAT3, and STAT5 gel shift assays: HIF-1, 5'-Cy5-AGTTGAGGGGACTTTCCCAGGC-3'; STAT1, 5'-Cy5-CATGTTATGCATATTCCTGTAAGTG-3'; STAT3, 5'-Cy5-GATCCTTCTGGGAATTCCTAGATC-3', and STAT5 5'-Cy5AGATTTCTAGGAATTCAATCC-3'. Specificity was confirmed by the addition of a 50-fold excess of either unlabeled specific competitor (specific probes without the Cy5 label) or unlabeled nonspecific competitor (5'-GACGTATGAGTCAGTCCA-3'). HIF-1 supershifts were performed by using a polyclonal antibody against HIF-1 $\alpha$ (Santa Cruz Biotechnology). Ten microliters of the mixture were separated on a $5 \%$ nondenaturing polyacrylamide gel at $4^{\circ} \mathrm{C}$ in $1 \times \mathrm{TBE}(90 \mathrm{~mm}$ Tris-borate and 2 mM EDTA, pH 8.3), using an external temperature-regulated ALF-Express DNA sequencer. Gels were analyzed directly by ALFwin and Allelix software (Amersham Biosciences) as described previously (Ruscher et al., 2000).

Quantitative competitive RT-PCR of EPO $m R N A$. Total cellular RNA was isolated from $\sim 10^{6}$ cells according to a modified method described by Chomczynski and Sacchi (1987), using Trizol reagent (Life Technology, Karlsruhe, Germany). Contaminating DNA was removed by incubating the RNA with DNase (Promega, Madison, WI) as recommended by the supplier. Integrity of the RNA was verified by gel electrophoresis, and RNA quantity was determined by optical density measurement. Reverse transcription of extracted RNA was performed by standard procedures, using Maloney murine leukemia virus reverse transcriptase (Promega). Using the housekeeping gene $\beta$-actin as an internal standard for RNA preparation and reverse transcriptase reaction, we performed quantitative competitive RT-PCR as described recently (Prass et al., 2002).
Quantitative real time RT-PCR of Bag-1, Bcl- $X_{L}, B c l-2$, Bax, and Bad. For evaluation of Bag-1, Bcl- $\mathrm{X}_{\mathrm{L}}, \mathrm{Bcl}-2$, Bax, and Bad gene expression, real time TaqMan RT-PCR was performed. At first, total RNA was prepared from cultured cells and was reverse transcribed into cDNA as described above for EPO RT-PCR. Expression of each sample was normalized on the basis of its $\beta$-actin mRNA content. In TaqMan assays a specific oligonucleotide probe is annealed to a target sequence located between the two primer binding sites. The probe is labeled with a reporter dye (FAM) at the $5^{\prime}$ end and a quencher dye at the $3^{\prime}$ end (TAMRA). The real-time PCR amplifications were performed in $25 \mu \mathrm{l}$ reaction volumes containing $1 \mu \mathrm{l}$ cDNA, $2.5 \mu \mathrm{l} 10 \times$ PCR buffer, $200 \mu \mathrm{M}$ each dATP, dCTP, dGTP, $400 \mu \mathrm{M}$ dUTP, $5 \mathrm{~mm} \mathrm{MgCL}$, and $0.25 \mathrm{U}$ Ampli-Taq DNA polymerase and AmpErase uracil $N$-glycosylase (UNG). The thermal cycling conditions included $2 \mathrm{~min}$ at $50^{\circ} \mathrm{C}$ and $10 \mathrm{~min}$ at $95^{\circ} \mathrm{C}$. Thermal cycling proceeded with 40 cycles of $95^{\circ} \mathrm{C}$ for $0.5 \mathrm{~min}$ and $60^{\circ} \mathrm{C}$ for $2 \mathrm{~min}$. All reactions were performed in duplicate; for amplification and detection an ABI Prism 7700 Sequence Detection System (PerkinElmer Applied Biosystems, Emeryville, CA) was used. Real-time data were analyzed with Sequence Detection Systems software, version 1.7. Each run contains both negative (no template) and positive controls. The following sequence-specific primers were used in RT-PCR. For $\beta$-actin: forward, $5^{\prime}$-GTACAACCTCCTTGCAGCTCCT-3'; reverse, 5'-TTGTCGACGACGAGCGC-3'; probe, 5'-CGCCACCAGTTCGCCATGGAT-3'. For Bag-1: forward, 5'-CAGCTAACCACCTGGAAGAGTTG-3'; reverse, 5'-GAGCCTCCGCTTGTAATTCCTT-3'; probe, 5'-TTCTGACATCCAGCAGGGTTTTCTGGC3'. For Bcl- $\mathrm{X}_{\mathrm{L}}$ : forward, 5'-GGTGAGTCGGATTGCAAGTTG-3'; reverse, 5'-GTAGAGATCCACAAAAGTGTCCCAG-3'; probe, 5'CCTGAATGACCACCTAGAGCCTTGGATCC-3'. For Bcl-2: forward, 5'-TGAACCGGCATCTGCACA-3'; reverse, 5'-CAGAGGTCGCATGCTGGG-3'; probe, 5'-AACGGAGGCTGGGATGCCTTTGTG-3'. For Bax: forward, 5'-GCGTGGTTGCCCTCT TCTACTT-3'; reverse, 5'AGCAGCCGCTCACGGAG-3'; probe, 5'-CAAACTGGTGCTCAAGGCCCTGTG-3'. For Bad: forward, 5'-CAGGCAGCCAACAACAGTCA-3'; reverse, 5'-CGCTGGGTACGAACTGTGG-3'; probe, 5'-CATGGAGGCGCTGGGACTATGGAGA-3'.

Western blotting. Cells were harvested in cell lysis buffer [containing (in mM) 20 Tris, pH 7.5, $150 \mathrm{NaCl}, 1$ EDTA, 1 EGTA, 2.5 sodium pyrophosphate, $1 \beta$-glycerol phosphate, $1 \mathrm{Na}_{3} \mathrm{VO}_{4}$, and 1 PMSF plus $1 \%$ Triton X-100, $1 \mu \mathrm{g} / \mathrm{ml}$ leupeptin]. After incubation on ice for $15 \mathrm{~min}$ and centrifugation at $18,000 \times g$ at $4^{\circ} \mathrm{C}$ for $10 \mathrm{~min}$, whole protein concentrations were determined by the BCA assay (Pierce, Rockford, IL), using bovine serum albumin as a standard. Cell lysates were diluted in SDS sample buffer (final concentrations: $62.5 \mathrm{~mm}$ Tris-HCl, $\mathrm{pH}$ 6.8, 2\% SDS, $10 \%$ glycerol, $50 \mathrm{~mm}$ DTT, $0.1 \%$ bromphenol blue), and the mixture was boiled for $5 \mathrm{~min}$. Protein $(30 \mu \mathrm{g})$ was separated on a $10 \%$ SDSpolyacrylamide gel. Blocking was performed onto polyvinyldifluoride membranes with blocking buffer $(20 \mathrm{~mm}$ Tris, $136 \mathrm{~mm} \mathrm{NaCl}, \mathrm{pH} 7.6$, $0.1 \%$ Tween $20,5 \%$ nonfat dry milk), and detected by using primary polyclonal antibodies against Bad, phospho-Bad $\left(\operatorname{Ser}^{136}\right)$, phospho-p38 mitogen-activated protein kinase (MAPK), and phospho-p44/42 MAPK (diluted 1:1000; all purchased from New England Biolabs, Frankfurt, Germany) and a polyclonal antibody against EPO (diluted 1:1000; Santa Cruz Biotechnology). After incubation overnight at $4^{\circ} \mathrm{C}$ the signals were obtained by binding of a secondary anti-rabbit HRP-linked antibody and were visualized on x-ray films (Hyperfilm, Amersham Biosciences), using a chemiluminescence kit (New England Biolabs). These experiments were repeated three times with similar results.

Akt kinase assay. Cortical neurons were treated with $100 \mathrm{U} / 1 \mathrm{rhEPO}$. In parallel experiments, $2.5 \mu \mathrm{g} / \mathrm{ml} \mathrm{sEpoR}$ or $10 \mu \mathrm{M}$ LY294002 was coapplied with $100 \mathrm{U} / 1 \mathrm{rhEPO}$ to the neuronal culture medium. After incubation for $30 \mathrm{~min}$ the cells were harvested in lysis buffer, and an Akt kinase assay was performed according to the instruction manual of the supplier (New England Biolabs).

\section{RESULTS \\ rhEPO time- and dose-dependently protects neurons from OGD}

Cultured rat cortical neurons expressed EpoR (Fig. 1A). rhEPO induced tolerance against OGD in a dose-dependent manner. Primary cortical neurons were pretreated with different concentrations of rhEPO $(1,10,100 \mathrm{U} / \mathrm{l})$ for $48 \mathrm{hr}$. As illustrated in Figure $1 B$, only the highest concentration of rhEPO afforded 


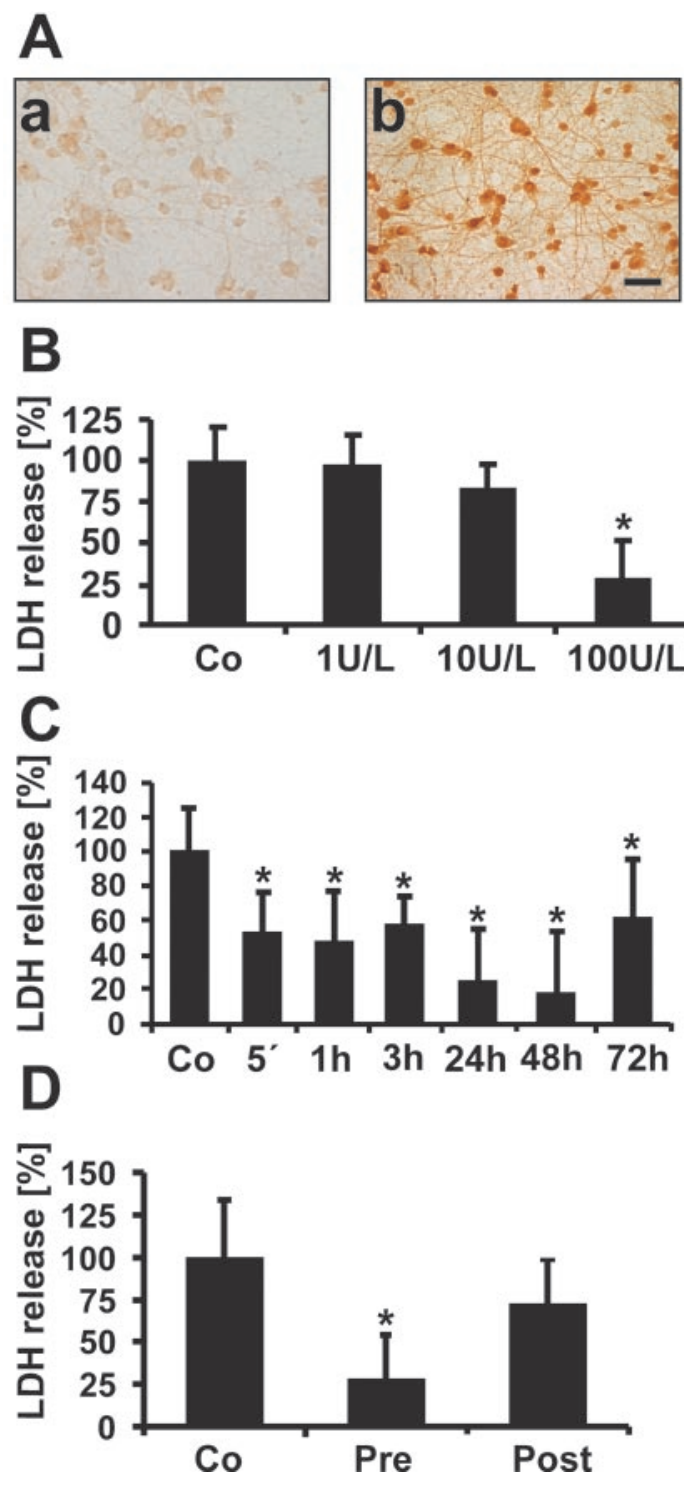

Figure 1. Primary cortical neurons express the erythropoietin receptor (EpoR), and human recombinant EPO (rhEPO) dose- and timedependently induces tolerance against OGD in primary cortical neurons. $A$, Primary cortical neurons express EpoR; expression of EpoR was analyzed by immunocytochemistry in primary cultures of cortical neurons. $a$, Unstained control (omission of primary antibody). $b$, Expression of EpoR on neurons after staining with a polyclonal antibody against EpoR (magnification, $400 \times$ ). Scale bar, $50 \mu \mathrm{m}$. B, rhEPO dose-dependently induces tolerance against OGD in primary cortical neurons. Before $120 \mathrm{~min}$ of OGD primary cortical neurons were pretreated for $48 \mathrm{hr}$ with 1,10 , or 100 $\mathrm{U} / 1 \mathrm{rhEPO}$, respectively. rhEPO (100 U/1) significantly protected primary cortical neurons from cell death. $C$, rhEPO time-dependently induces tolerance against OGD in primary cortical neurons. Pretreatment with 100 $\mathrm{U} / \mathrm{l} \mathrm{rhEPO}$ for the indicated intervals induced a fast and prolonged neuroprotection. After $5 \mathrm{~min}$ of EPO exposure the neurons already were protected from OGD-induced cell death by $50 \%$. The maximum of protection was observed after a pretreatment period of 24 and $48 \mathrm{hr} . D$, Compared with EPO-untreated OGD control neurons ( $\mathrm{Co}$ ), preincubation of neurons with $100 \mathrm{U} / 1 \mathrm{EPO}$ for $48 \mathrm{hr}$ resulted in a statistically significant reduction of cell death $24 \mathrm{hr}$ after lethal OGD (Pre), whereas posttreatment with $100 \mathrm{U} / 1$ EPO immediately after lethal OGD was not neuroprotective (Post). Cell death in $B-D$ was measured as $L D H$ release into the medium for $24 \mathrm{hr}$ after OGD. Data were obtained from three independent experiments with 16 cell cultures each; data were normalized and presented as means \pm SD. Multiple comparisons (Dunn's method) were performed after Kruskal-Wallis one-way ANOVA on ranks $\left({ }^{*} p>0.05\right.$ vs Co). Normoxic (BSS) stimulation was set to $0 \%$ cell death and OGD stimulation $(\mathrm{Co})$ to $100 \%$ cell death, respectively.

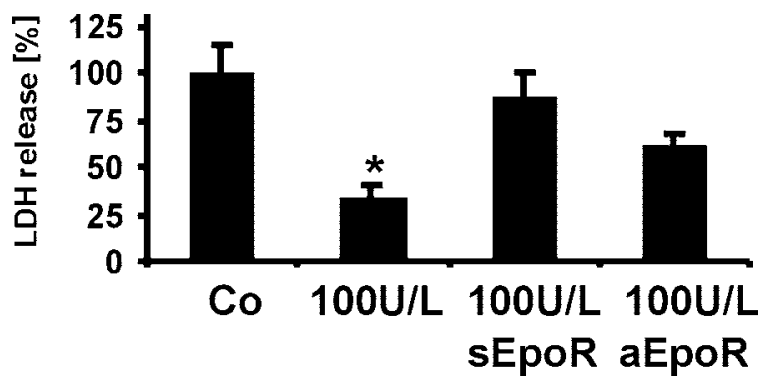

Figure 2. EPO-induced neuroprotection is mediated by interaction with the cognate receptor of EPO. Neuroprotection induced by pretreatment with $100 \mathrm{U} / 1 \mathrm{rhEPO} 48 \mathrm{hr}$ before lethal OGD (120 min) was inhibited by the coapplication of either a soluble erythropoietin receptor $(s E p o R)$ or an antibody against the erythropoietin receptor (anti-EpoR, aEpoR). Cell death was measured as LDH release into the medium for $24 \mathrm{hr}$ after OGD. Data were obtained from three independent experiments with 16 cell cultures each; data were normalized and presented as means \pm SD. Multiple comparisons (Dunn's method) were performed after KruskalWallis one-way ANOVA on ranks $\left({ }^{*} p>0.05\right.$ vs all other groups). Normoxic (BSS) stimulation was set to $0 \%$ cell death and OGD stimulation $(\mathrm{Co})$ to $100 \%$ cell death, respectively.

statistically significant neuronal survival after 120 min of OGD, as assessed $24 \mathrm{hr}$ later by LDH assay (75\% protection).

To examine the time dependence of neuroprotection by EPO, we pretreated neurons with $100 \mathrm{U} / 1 \mathrm{rhEPO}$ from $5 \mathrm{~min}$ to $72 \mathrm{hr}$ before OGD. Surprisingly, even a 5 min incubation period already afforded tolerance against OGD in neurons (Fig. $1 C$ ). The highest levels of protection were achieved after $48 \mathrm{hr}$ of incubation with rhEPO. Longer intervals were associated with a decreasing level of protection, most probably related to a reduced viability of the cultures because of the prolonged cultivation period. In contrast to EPO preincubation, the addition of EPO to primary cortical neurons immediately after lethal OGD (120 min) had no statistically significant neuroprotective effect (Fig. 1D).

To test whether neuroprotection is mediated by the specific interaction of EPO with its cognate receptor, we coapplied 100 U/1 rhEPO either with a soluble EPO receptor (sEpoR) or with an antibody against the EPO receptor (anti-EpoR). Both sEpoR or anti-EpoR blocked EPO-induced ischemic tolerance (Fig. 2). EPO-induced protection and specific blockade of this protection are illustrated by representative fluorescent micrographs of OGD-challenged neurons stained with ethidium bromide/acridine orange (Fig. $3 A$ ). In accordance with our previous results (Ruscher et al., 1998), the predominant cell death in our OGD model was apoptosis. Using a TUNEL assay, we demonstrated that rhEPO blocks OGD-induced neuronal apoptosis (Fig. 3B). To substantiate the anti-apoptotic effect of EPO further, we analyzed its effect on DNA fragmentation. Preincubation with 100 U/1 EPO significantly reduced DNA fragmentation induced by OGD (Fig. 3C). sEpoR as well as anti-EpoR was able to block the anti-apoptotic effect of EPO (Fig. 3B,C).

\section{Erythropoietin produced by astrocytes mediates neuroprotection against oxygen glucose deprivation}

Astrocytes are the major source of EPO production in the brain (see introductory remarks). We therefore investigated EPO expression in astrocytes exposed to OGD for $180 \mathrm{~min}$. Pilot experiments indicated that the degree of EPO induction in astrocytes after OGD was not higher at 180 min compared with $60 \mathrm{~min}$. At $48 \mathrm{hr}$ after OGD the astrocytes showed no reduced viability when analyzed for morphological changes or lactate dehydrogenase 

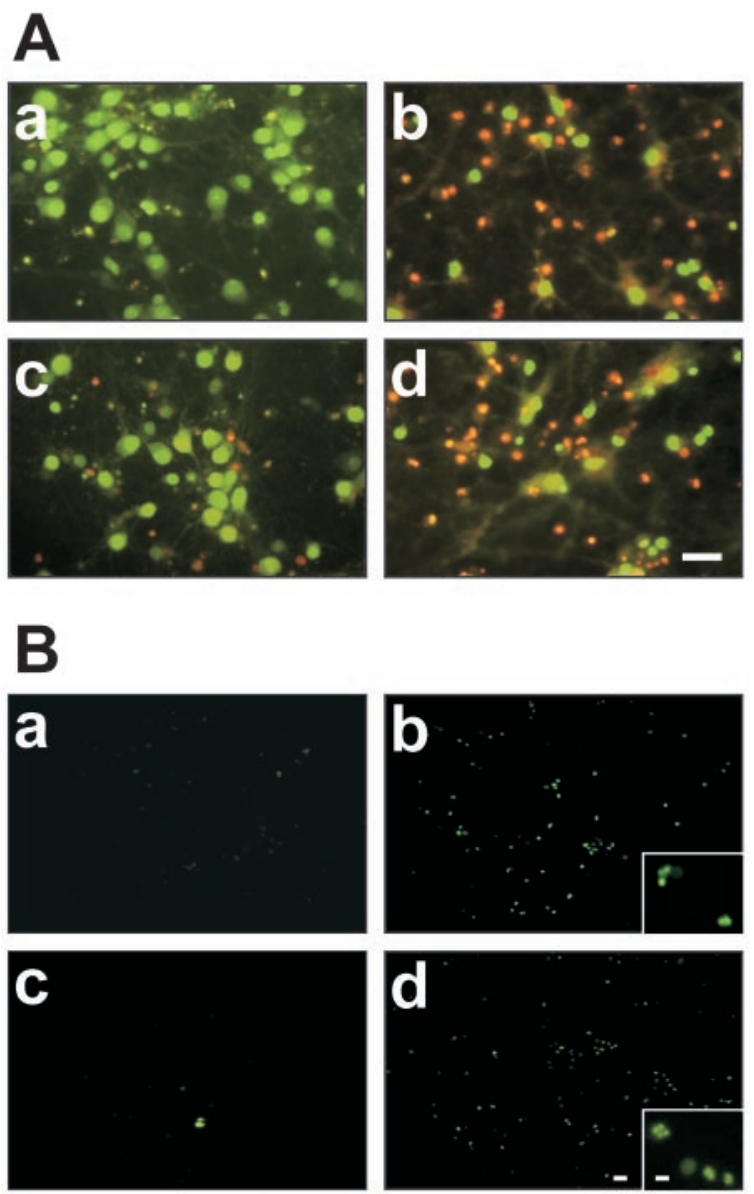

C

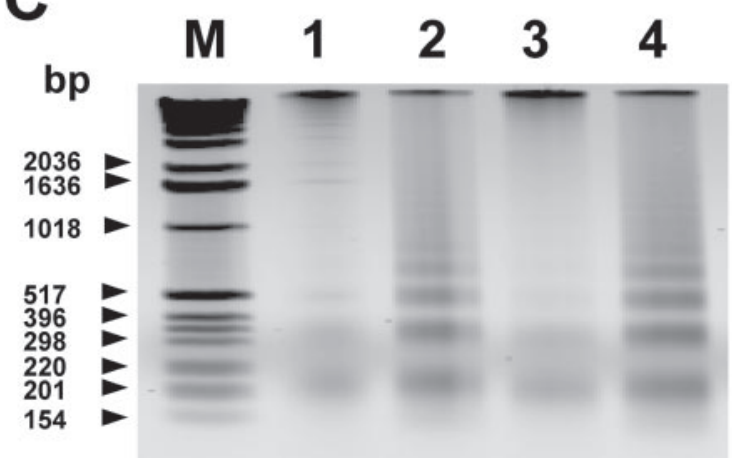

Figure 3. Fluorescence microscopy $(A)$, TUNEL assay $(B)$, and DNA laddering $(C)$ demonstrate the neuroprotective effect of EPO in OGDinduced neuronal apoptosis. Shown are micrographs of ethidium bromide/acridine orange-stained $(A$; magnification $400 \times)$ and TUNELstained $(B$; magnification $200 \times)$ primary cortical neurons $24 \mathrm{hr}$ after OGD with or without EPO pretreatment. $a$, Normoxic control; $b$, OGD for 120 min without EPO pretreatment; $c$, OGD for 120 min with EPO pretreatment. Cultured neurons were stimulated by $100 \mathrm{U} / 1 \mathrm{rhEPO} 48 \mathrm{hr}$ before $120 \mathrm{~min}$ of OGD. $d$, OGD for $120 \mathrm{~min}$ with EPO pretreatment and block by anti-EpoR. Stimulation of cultured neurons by $100 \mathrm{U} / 1 \mathrm{rhEPO} 48$ hr before $120 \mathrm{~min}$ of OGD was blocked by the coapplication of $2.5 \mu \mathrm{g} / \mathrm{ml}$ anti-EpoR. The insets (magnification $400 \times$ ) in micrographs $B b$ and $B d$ demonstrate apoptotic bodies. Scale bars: (in $d$ ) $a-d, 50 \mu \mathrm{m}$; inset, $20 \mu \mathrm{m}$. $C$, OGD-induced DNA fragmentation was abolished by pretreatment with EPO. DNA fragmentation was analyzed $24 \mathrm{hr}$ after lethal OGD (120 $\mathrm{min}$ ) of primary cortical neurons with or without EPO pretreatment. Lane M, $1 \mathrm{~kb}$ ladder; lane 1, BSS-treated cells; lane 2, OGD-treated cells; lane 3 , OGD-treated cells preincubated with $100 \mathrm{U} / 1 \mathrm{rhEPO} 48 \mathrm{hr}$ before OGD; lane 4, OGD-treated cells preincubated with $100 \mathrm{U} / 1 \mathrm{rhEPO}$ and $2.5 \mu \mathrm{g} / \mathrm{ml} \mathrm{sEpoR} 48 \mathrm{hr}$ before OGD.
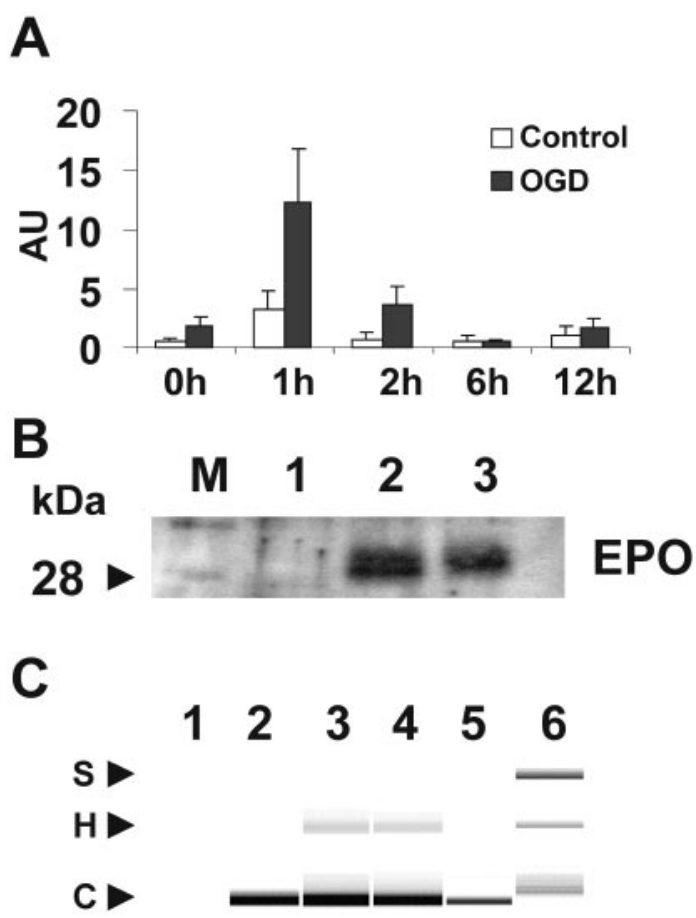

Figure 4. Astrocytic HIF-1 activation and erythropoietin expression are sequential events that follow oxygen glucose deprivation. $A$, Astrocytes produce erythropoietin in response to OGD. Astrocytes were stimulated by OGD or control conditions for $180 \mathrm{~min}$. Shown are different time points after OGD cells were harvested and total RNA was isolated and reverse transcribed. Using a quantitative competitive RT-PCR approach and the housekeeping gene $\beta$-actin as an internal standard, we determined EPO mRNA expression. Data were obtained from three independent experiments, presented as the means $\pm \mathrm{SD}$ of arbitrary units $(A U) . B$, In accordance with the mRNA expression of EPO, the protein was detectable $60 \mathrm{~min}$ after OGD. Shown are Western blot analysis from control astroglial cultures (lane 1), OGD-stimulated cultures (lane 2), and positive control (lane 3). The molecular size of the protein standard (lane $M$ ) is indicated. $C$, Induction of astroglial EPO expression is associated with the preceding induction of HIF-1 binding activity. Astrocytes were stimulated by OGD or control conditions for $180 \mathrm{~min}$. Nuclear extracts were prepared immediately, and $30 \mu \mathrm{g}$ of each was tested for HIF-1 DNA binding activities, using an fEMSA approach. Shown are probes without nuclear extract (lane 1), probes and nuclear extracts from BSS-stimulated astrocytes (lane 2), probes and nuclear extracts from OGD-stimulated astrocytes (lane 3 ), probes and nuclear extract from OGD-stimulated astrocytes and the addition of an unspecific competitor (lane 4; 50-fold), probes and nuclear extract from OGD-stimulated astrocytes and the addition of a specific competitor (lane 5; 50-fold), and probes and nuclear extract from OGDstimulated astrocytes and the addition of a specific antibody against HIF-1 $\alpha$ (lane 6). $C$, Constitutive DNA binding activity; $H$, specific HIF-1 DNA complex; $S$, supershifted HIF-1 DNA complex.

release (data not shown). For measurement of EPO mRNA expression we used a competitive RT-PCR approach. In response to OGD the astrocytes very rapidly express EPO mRNA. Already at $60 \mathrm{~min}$ after $\mathrm{OGD}$ the expression reached a maximum with a 12-fold induction over baseline (Fig. 4A). This was accompanied by a strong induction of EPO protein (Fig. $4 B$ ). Control was defined as astrocytes treated with basic salt solution under normoxic conditions, whereas baseline expression was taken from astrocytes before all manipulation (see Materials and Methods).

Because EPO expression is controlled mainly by the transcription factor HIF-1 (Semenza, 2000), we investigated whether the activation of HIF-1 precedes EPO expression. Using a fluorescent-based electrophoretic mobility shift assay (fEMSA; Ruscher et al., 2000), we observed marked HIF-1 DNA binding 


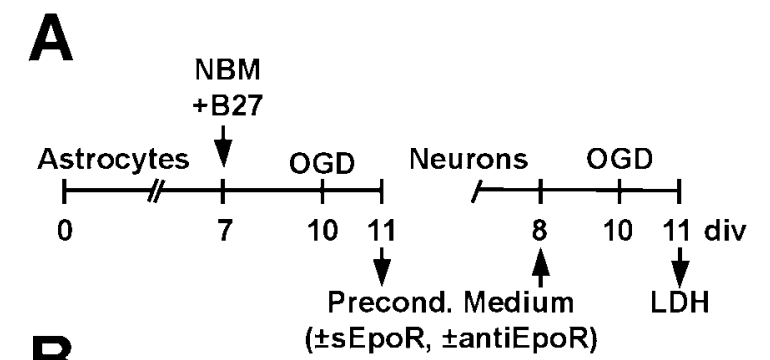

B

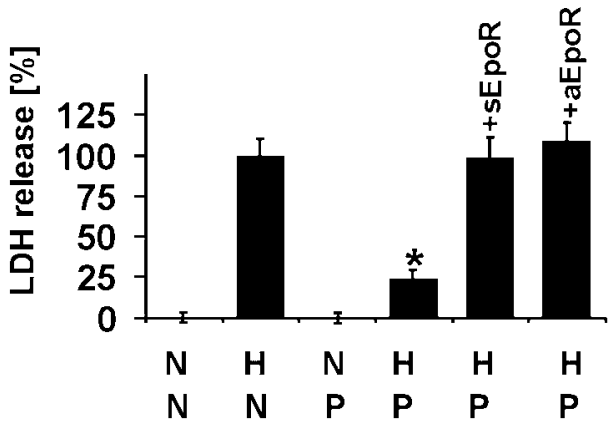

Figure 5. Preconditioned medium from astrocytes induces ischemic tolerance in cortical neurons. $A$, Experimental paradigm. Astrocytes were stimulated for 180 min either by OGD (preconditioning) or with BSS medium under normoxia (no preconditioning), and media were harvested $24 \mathrm{hr}$ later. $B$, Neuronal cultures, pretreated with medium either from OGD-stimulated (preconditioning, $P$, bottom row) or from BSSstimulated (no preconditioning, $N$, bottom row) astrocytes for $48 \mathrm{hr}$, were exposed to OGD (H, top row) or BSS ( $N$, top row) for $120 \mathrm{~min}$, respectively. Cell death, measured as LDH release into the medium for $24 \mathrm{hr}$ after OGD, was reduced significantly by OGD-conditioned medium from astrocytes. This neuroprotection was diminished by $2.5 \mu \mathrm{g} / \mathrm{ml} \mathrm{sEpoR}$ and $2.5 \mu \mathrm{g} / \mathrm{ml}$ anti-EpoR, indicating that EPO is the neuroprotective factor. Data were obtained from three independent experiments with 16 cell cultures each; data were normalized and presented as means $\pm \mathrm{SD}$. Multiple comparisons (Dunn's method) were performed after KruskalWallis one-way ANOVA on ranks $\left({ }^{*} p>0.05\right.$ vs N/H, $\mathrm{P} / \mathrm{H}+\mathrm{sEpoR}$, or $\mathrm{P} / \mathrm{H}+\mathrm{aEpoR}) . N$ represents normoxic (BSS) and $H$ represents hypoxic (OGD) treatment. $N / N$ treatment was set to $0 \%$ cell death and $N / H$ treatment to $100 \%$ cell death, respectively.

activity in nuclear extracts from astrocytes after OGD stimulation for $180 \mathrm{~min}$ (Fig. 4C). The specificity of the HIF-1 binding was tested by competition experiments that used an unlabeled HIF-1 probe or nonspecific probe and was tested by supershift experiments, using an antibody against HIF-1 $\alpha$ (Fig. $4 C$ ).

We next investigated whether OGD-treated astrocytes release a factor capable of protecting neurons from OGD and whether this factor is EPO. Astrocytes were subjected to $180 \mathrm{~min}$ of OGD, after which they were allowed to condition medium for $24 \mathrm{hr}$. Subsequently, conditioned medium was transferred to neuronenriched cultures, and the neurons were exposed to this medium for $48 \mathrm{hr}$. Conditioned medium was washed out before the neurons were exposed to OGD of $120 \mathrm{~min}$, which is lethal for $\sim 75 \%$ of neurons. Preincubation with the OGD-conditioned astrocyte medium protected neurons from OGD (Fig. 5A,B). LDH assay 24 hr after OGD demonstrated a $75 \%$ increase in neuronal viability compared with "control-conditioned" medium. Medium transferinduced neuronal protection was blocked completely by sEpoR or anti-EpoR, indicating that EPO is the neuroprotective factor released by OGD-stimulated astrocytes (Fig. 5A,B). This was verified by using an EPO immunoassay. The OGD-conditioned astrocyte medium contained $258 \mathrm{U} / 1 \mathrm{EPO}$, which is comparable with the neuroprotective concentrations of rhEPO in this and
A
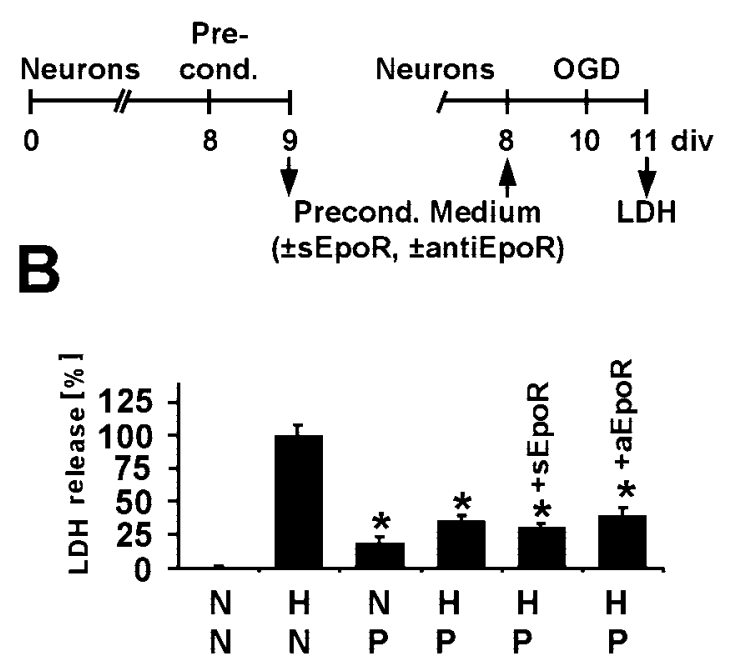

Figure 6. Neuro-neuronal preconditioning is not mediated by erythropoietin. A, Experimental paradigm. Cortical neurons were stimulated either by OGD for $60 \mathrm{~min}$ (preconditioning) or with BSS medium under normoxia (no preconditioning), and both media were harvested $24 \mathrm{hr}$ later. $B$, Neuronal cultures, pretreated with medium either from OGDstimulated (preconditioning, $P$, bottom row) or from BSS-stimulated (no preconditioning, $N$, bottom row) cortical neurons for $48 \mathrm{hr}$, were exposed to $\mathrm{OGD}(H$, top row) or BSS $(N$, top row) for $120 \mathrm{~min}$. Cell death, measured as $\mathrm{LDH}$ release into the medium for $24 \mathrm{hr}$ after OGD, was reduced significantly in neuronal cultures treated with OGD-conditioned medium from neurons. However, this neuroprotection was diminished neither by $2.5 \mu \mathrm{g} / \mathrm{ml}$ sEpoR nor by $2.5 \mu \mathrm{g} / \mathrm{ml}$ anti-EpoR, excluding EPO as the neuroprotective factor. Data were obtained from three independent experiments with 16 cell cultures each; data were normalized and presented as means \pm SD. Multiple comparisons (Dunn's method) were performed after Kruskal-Wallis one-way ANOVA on ranks ( ${ }^{*} p>0.05$ vs $\mathrm{N} / \mathrm{H}$ treatment). $N$ represents normoxic (BSS) and $H$ represents hypoxic (OGD) treatment. $N / N$ treatment was set to $0 \%$ cell death and $N / H$ treatment to $100 \%$ cell death, respectively.

other studies. sEpoR and anti-EpoR had no effect of their own on neuronal cell viability (data not shown).

\section{Neuron-to-neuron transfer of protection is not mediated by EPO}

We have shown previously that primary neurons in culture can be preconditioned by OGD in the presence of $<10 \%$ astrocytes (Bruer et al., 1997; Ruscher et al., 1998). We therefore investigated whether EPO also is involved in OGD preconditioning of enriched neurons in culture. Neurons were subjected to a preconditioning interval of OGD (90 min) after which they were allowed to condition medium for $24 \mathrm{hr}$ (Fig. 6A). Transfer of this medium to naive neuron-enriched cultures and subsequent exposure for 48 hr conferred protection to neurons against a normally lethal OGD (120 min). Thus neurons, like astrocytes, release protective factor(s). However, in this case EPO is not involved, because neither sEpoR nor anti-EpoR affected the protective effect (Fig. $6 A, B)$. In line with this finding and in contrast to astrocytes, we observed no induction of EPO-mRNA in neurons after a preconditioning OGD period of $60 \mathrm{~min}$ when we used our competitive RT-PCR approach (data not shown). In addition, using an EPO immunoassay, we could not detect any EPO protein in the medium preconditioned by neurons. 


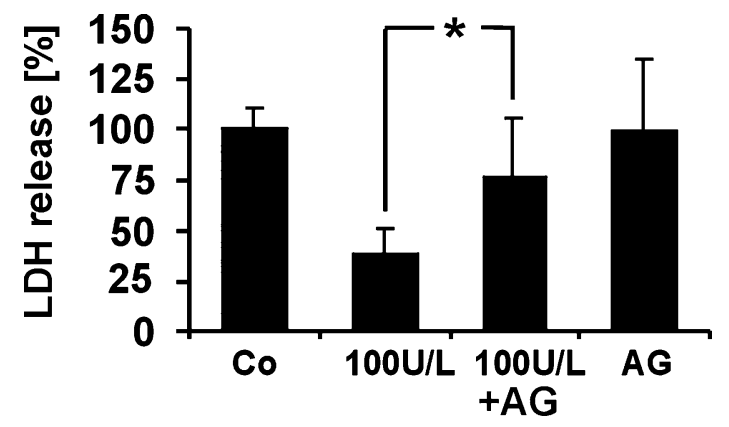

Figure 7. Erythropoietin-induced neuroprotection is mediated by Janus kinase-2 (JAK-2). Cortical neurons, pretreated with $100 \mathrm{U} / 1 \mathrm{rhEPO}$ and/or AG490 (5 $\mu \mathrm{M})$ for $48 \mathrm{hr}$, were exposed to $120 \mathrm{~min}$ of OGD or BSS. Coapplication of the JAK-2 inhibitor AG490 abolished the neuroprotective effect of $100 \mathrm{U} / 1 \mathrm{rhEPO}(100 \mathrm{U} / \mathrm{l}$ vs $100 \mathrm{U} / \mathrm{l}+A G)$. Neuronal viability under hypoxic $(A G)$ or normoxic (data not shown) conditions is not altered by JAK-2 inhibition alone. Cell death was measured as LDH release into the medium for $24 \mathrm{hr}$ after OGD. Data were obtained from three independent experiments with eight cell cultures each; data were normalized and presented as means $\pm \mathrm{SD}\left({ }^{*} p>0.05\right.$ vs $100 \mathrm{U} / 1 \mathrm{EPO}$; Mann-Whitney rank sum test). Normoxic (BSS) stimulation was set to $0 \%$ cell death and OGD stimulation $(\mathrm{Co})$ to $100 \%$ cell death, respectively.

\section{Activation of Janus kinase-2 pathway mediates the neuroprotective effect of EPO}

Janus kinase-2 (JAK-2) is the key kinase in the signal transduction pathways activated by the EpoR. Therefore, we explored the role of JAK-2-dependent pathways for the anti-apoptotic effect of EPO on OGD-induced apoptosis in neurons. As shown in Figure 7, rhEPO-induced neuroprotection is attenuated significantly in the presence of the specific JAK-2 inhibitor AG490 (5 $\mu \mathrm{M})$. AG490 alone had no effect on neuronal viability. These results strongly suggest a central role of JAK-2 in EPO-mediated neuroprotection.

\section{STATs and MAPK pathways are not involved in EPO-mediated neuroprotection}

Downstream from JAK-2 at least three different signaling pathways have been implicated in EPO-induced protection from apoptosis: STAT, Ras/MAP kinase, and phosphoinositide-3 kinase (PI3K). First we analyzed the JAK-2/STAT pathway. In nonneuronal tissues EPO can activate the STAT family members STAT1, STAT3, and STAT5 rapidly. Although STAT1, STAT3, and STAT5 have been implicated in the regulation of apoptosis of non-neuronal tissues (Grad et al., 2000), only STAT5 so far has been demonstrated in the anti-apoptotic signaling of Epo (Socolovsky et al., 1999; Constantinescu et al., 2001), whereas only STAT3 is expressed constitutively throughout the brain in glial cells as well as neurons (Murata et al., 2000). Surprisingly, 30 min after rhEPO stimulation we did not find any DNA binding activity of STAT1, STAT3, or STAT5 (Fig. 8A). To exclude that STAT transactivation was short and transient and thus may have been missed, we investigated the mRNA expression of STATtransactivated anti-apoptotic genes, known to be involved in receptor tyrosine kinase-induced anti-apoptotic pathways. For mRNA quantification we used a real-time RT-PCR approach and the housekeeping gene $\beta$-actin as an internal standard. In accordance with our negative STAT data, EPO did not induce Bcl-2, Bcl- $\mathrm{X}_{\mathrm{L}}$, or Bag-1 transcription in cortical neurons, neither after 12 nor after $48 \mathrm{hr}$ of Epo application (Fig. 8B).

Next we investigated a possible involvement of MAPK pathways, the extracellular-regulated protein kinase (ERK or p42/44),

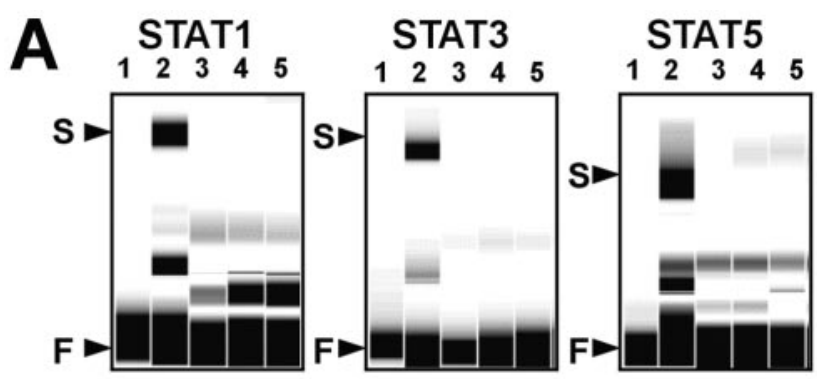

B
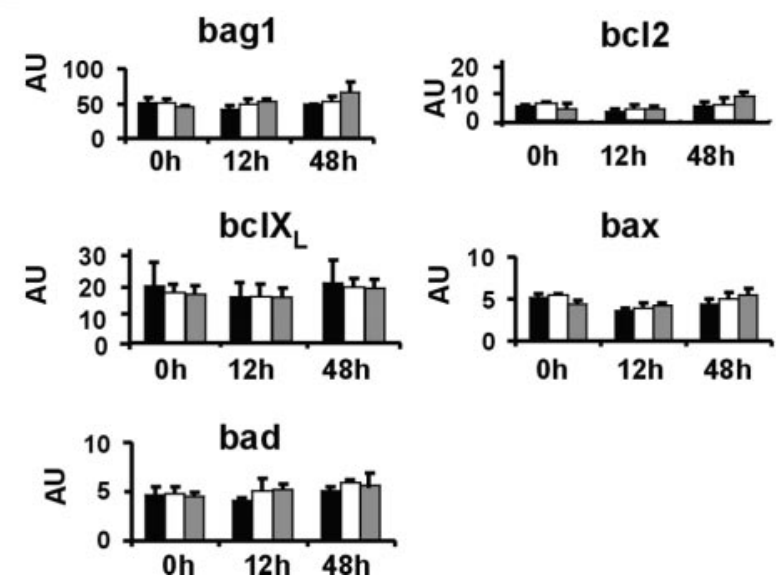

Figure 8. JAK-2/STAT pathway is not involved in EPO-mediated neuroprotection. $A$, EPO stimulation of neurons does not activate the transcription factors STAT1, STAT3, and STAT5, as assessed by fEMSA. Shown are probes without nuclear extract (lane 1); probes and positive controls for STAT1 from phorbol ester-treated HeLa cells and for STAT3 and STAT5 from phorbol ester-treated K562 cells (lane 2); probes, positive controls, and a 50-fold excess of specific competitor against STAT1, STAT3, or STAT5, respectively (lane 3); probes and extract from untreated neurons (lane 4 ); and probes and extract from neurons treated by $100 \mathrm{U} / 1 \mathrm{rhEPO}$ for $30 \mathrm{~min}$ (lane 5). $F$, Free probe; $S$, specific protein DNA complex. $B$, Transcriptional pattern of anti- and pro-apoptotic Bcl-2 family genes is not altered in neurons by erythropoietin stimulation. Cortical neurons were stimulated by $100 \mathrm{U} / 1 \mathrm{rhEPO}$ for 0,12 , or $48 \mathrm{hr}$, respectively. EPO-stimulated neurons (black columns) were compared with untreated control neurons (white columns) and with neurons treated with the combination of $100 \mathrm{U} / 1 \mathrm{rhEPO}$ and $2.5 \mu \mathrm{g} / \mathrm{ml} \mathrm{sEpoR}$ (gray columns). Using a quantitative real-time RT-PCR approach and the housekeeping gene $\beta$-actin as an internal standard, we found no induction or repression of mRNA expression of Bcl-2, Bcl- $\mathrm{X}_{\mathrm{L}}$, Bag-1, Bax, and Bad. Data were obtained from three independent experiments, presented as means $\pm \mathrm{SD}$ of arbitrary units $(A U)$.

and p38 mitogen-activated kinase (p38 MAPK) (Herlaar and Brown, 1999). None of these was activated (i.e., phosphorylated) after EPO stimulation (see Fig. 10).

EPO-induced neuronal preconditioning is mediated by the activation of a PI3K pathway and subsequent phosphorylation of Bad

We next evaluated whether EPO-induced neuroprotection involves the activation of PI3K. Cortical neurons were treated with $100 \mathrm{U} / 1 \mathrm{rhEPO}$ in the presence of LY294002 $(10 \mu \mathrm{M})$, a cellpermeable specific inhibitor of PI3 kinase. Thereafter, cultured neurons were exposed to a lethal OGD interval either 1 or $24 \mathrm{hr}$ after EPO/LY294002 pretreatment. As shown in Figure 9, the inhibition of PI3K significantly diminished EpoR-mediated neuroprotection in the short $(1 \mathrm{hr})$ as well as in the long $(24 \mathrm{hr})$ time window. In addition, we analyzed the effects on neuronal survival 

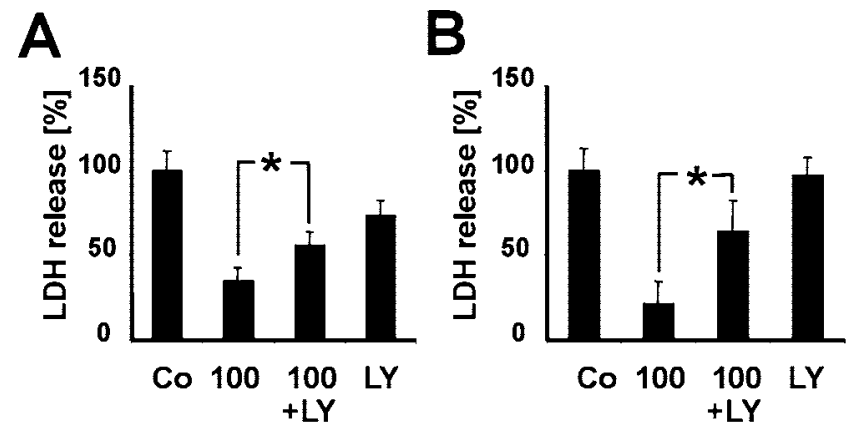

Figure 9. Erythropoietin-induced neuroprotection is mediated by phosphoinositol-3 kinase (PI3K). Pretreatment of neurons for a short (1 $\mathrm{hr}, A)$ and a prolonged $(24 \mathrm{hr}, B)$ incubation period with the specific PI3K inhibitor LY294002 $(10 \mu \mathrm{M})$ immediately before the application of 100 U/1 EPO partially abolished the neuroprotective effect of EPO against 120 min of OGD (100 U/1 vs 100 U/1 + LY). Pretreatment with LY294002 alone did not influence neuronal viability under hypoxic $(L Y)$ or normoxic (data not shown) conditions. Cell death was measured as LDH release into the medium for $24 \mathrm{hr}$ after OGD. Data were obtained from three independent experiments with eight cell cultures each; data were normalized and presented as means $\pm \mathrm{SD}\left({ }^{*} p>0.05\right.$ vs $100 \mathrm{U} / 1 \mathrm{EPO}$; Mann-Whitney rank sum test). Normoxic (BSS) stimulation was set to $0 \%$ cell death and OGD stimulation $(\mathrm{Co})$ to $100 \%$ cell death, respectively.

of LY294002 alone. LY294002 had no significant effect on neuronal viability, neither in OGD-treated (Fig. 9A,B) nor in untreated cortical neurons (data not shown).

The observation that EPO-induced neuroprotection is PI3Kdependent led us to test whether the activation of one of the major downstream effectors of PI3K, the serine-threonine protein kinase Akt, is correlated with the observed neuroprotection. Stimulation of cortical neurons with $100 \mathrm{U} / 1 \mathrm{rhEPO}$ for $30 \mathrm{~min}$ resulted in a marked activation of Akt, which was diminished significantly by sEpoR (Fig. 10). In addition, the activation of Akt induced by $100 \mathrm{U} / 1$ rhEPO was blocked completely in the presence of the specific PI3K inhibitor LY294002 (Fig. 10).

Bad has been identified as one major target of Akt, linking the PI3K pathway directly to the apoptotic machinery (Datta et al., 1999). We measured Bad phosphorylation by using a phosphospecific anti-Bad antibody that specifically recognizes the serine residue 136, because this residue has been shown to be a substrate of Akt kinase and thereby is sufficient to promote cell survival. As shown in Figure 10, a band corresponding to phosphorylated Bad was already present in untreated cultured neurons. However, after pretreatment of cortical neurons with $100 \mathrm{U} / 1 \mathrm{EPO}$ for 30 min, Bad phosphorylation increased significantly. EPO-induced Bad phosphorylation was diminished significantly after the blockade of EpoR by the application of sEpoR as well as after the specific inhibition of PI3K by LY294002 (Fig. 10). In all cases, Western blot analysis with a nonphospho-specific anti-Bad antibody showed that the protein levels of Bad were not altered by the treatment (Fig. 10), in accordance with our findings that EPO did not alter Bad transcription (Fig. 8). Furthermore, because Akt promotes survival in hippocampal neurons by preventing transcriptional activity of p53 and thereby blocking the induction of the proapoptotic Bcl-2 family member Bax (Yamaguchi et al., 2001), we tested whether EPO repressed Bax transcription. However, we found no repression of Bax transcription (Fig. 8).

\section{DISCUSSION}

The key findings of our study were that (1) astrocytes as well as neurons can release paracrine signals that induce protection

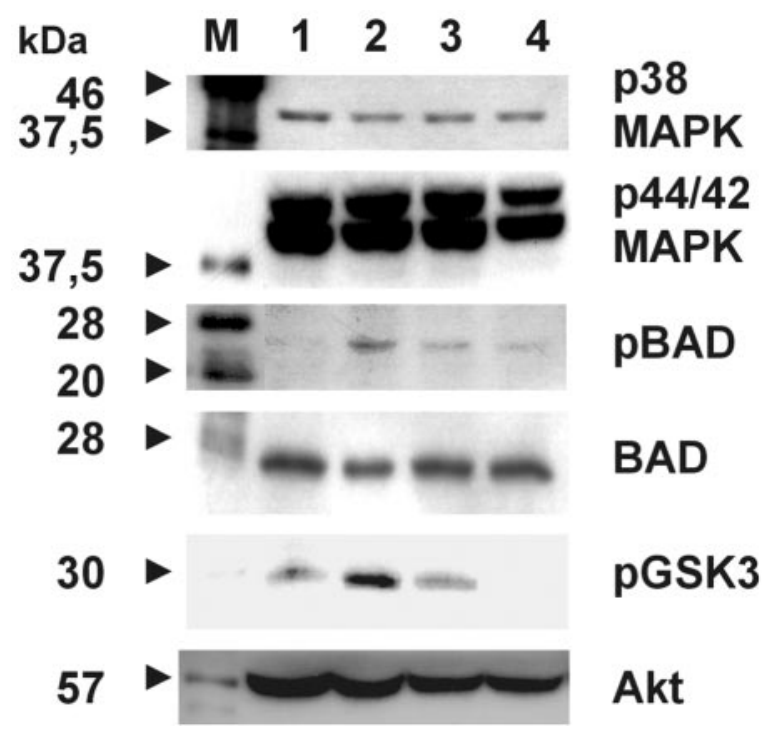

Figure 10. Erythropoietin-induced neuroprotection is associated with the activation of Akt kinase and the phosphorylation of BAD. rhEPO (100 U/l) for 30 min activated Akt kinase and phosphorylated BAD, but not p38 and p44/42 MAPK, in cortical neurons. EPO-induced activation of Akt kinase and BAD phosphorylation is blocked by $2.5 \mu \mathrm{g} / \mathrm{ml} \mathrm{sEpoR}$ as well as by the specific PI3K inhibitor LY294002 (10 $\mu \mathrm{M})$. Shown are Western blot analysis from control cultures (lane 1), EPO-stimulated cultures (lane 2), sEpoR- and EPO-treated cultures (lane 3), and LY294002- and EPO-treated cultures (lane 4). The molecular sizes of the protein standards (lane $M$ ) are indicated (left). GSK3 indicates the substrate protein in the Akt kinase assay.

against hypoxia/ischemia in neurons; (2) a key mediator of paracrine neuroprotection by astrocytes (but not neurons) is EPO, which acts via its cognate receptor; (3) EPO-induced neuroprotection is effective within minutes and can be sustained for many hours with continued EPO exposure; (4) in neurons, EPO induces neuroprotection via a protein phosphorylation cascade including JAK-2 and PI3K/Akt that may inactivate the proapoptotic Bcl2 family member Bad; however, (5) other well described protective signaling pathways of EPO (STATs, ERK) did not seem to play a significant role in our system.

We have to consider that our in vitro model may be more relevant for neonatal ischemia, although the OGD model is a standard in vitro model of adult cerebral ischemia. In addition, we have experimental evidence that points to effects of EPO in the adult brain that are responsible for protection in ischemic tolerance. Specifically, sEpoR (intracerebroventricularly) attenuates hypoxic preconditioning against focal cerebral ischemia in mice (K. Prass, U. Dirnagl, and A. Meisel, unpublished data). We are thus confident that the in vitro evidence presented here is relevant for the mammalian adult brain in vivo.

Bernaudin et al. (2000) have shown that EPO expression is induced by hypoxia in neurons as well as in astrocytes. Furthermore, desferrioxamine, an activator of HIF-1 and potent stimulator of IP in vitro and in vivo, induced EPO mRNA in neurons and in astrocytes (Zaman et al., 1999; Bergeron et al., 2000; Bernaudin et al., 2000). However, results allowing a comparison of absolute EPO expression levels in astrocytes and neurons do not exist. Our results suggest that only astrocytes, but not neurons, express and release sufficient amounts of EPO for paracrine neuroprotection. Importantly, although neurons expressed and released IP-mediating factor(s), in accordance with our negative transcriptional data we were able to rule out by pharmacological 
means (sEpoR and anti-EpoR) that EPO participates in interneuronal preconditioning. Liu et al. (2000) have identified a TNF- $\alpha$-mediated and ceramide synthesis-dependent pathway of IP in an OGD model very similar to ours, a mechanism that has been corroborated recently by the same group in vivo (Furuya et al., 2001). Because TNF- $\alpha$ is expressed in an IP model in vivo (Wang et al., 2000), this cytokine should be considered as a promising candidate responsible for the paracrine protective signaling from neurons to neurons.

Pretreatment of cultured neurons with rhEPO (30 and $300 \mathrm{pM}$ ) $24 \mathrm{hr}$ before exposure to NMDA led to a significant reduction of neuronal damage (Bernaudin et al., 1999). In "chronic" OGD models, with hypoxic intervals of up to $24 \mathrm{hr}$, rat cortical or hippocampal neurons (but not astrocytes) were protected in the presence of $30 \mathrm{pm}$ recombinant mouse EPO or $100 \mathrm{pm}$ rhEPO, respectively (Sinor and Greenberg, 2000; Sirén et al., 2001). Interestingly, in five patients with traumatic brain injuries Marti et al. (1997) reported EPO levels between 30 and 40 U/1 in CSF. The EPO doses used in previous in vitro studies and in human $\mathrm{CSF}$ are therefore in good agreement with our data, in which 100 $\mathrm{U} / 1 \mathrm{rhEPO}$ (corresponding to $30 \mathrm{pm}$ ) were effective. However, the design of these studies differed significantly from ours. First, our OGD stimulus was more severe, because $180 \mathrm{~min}$ of OGD was $100 \%$ lethal after $24 \mathrm{hr}$, whereas $\sim 50 \%$ of neurons survived OGD periods of $24 \mathrm{hr}$ in the model of Sinor and Greenberg (2000) and $15 \mathrm{hr}$ in the model of Sirén et al. (2001). Second, these authors analyzed the survival of OGD-treated neurons in the presence of EPO during hypoxia. In contrast, we pretreated cortical neurons with EPO, which was washed out before OGD. Third, we demonstrated for the first time a neuroprotective effect of endogenous EPO in vitro. Therefore, our findings add to what was already known concerning EPO-mediated neuroprotection in vitro: EPO does not have to be present during OGD for protection; it also protects against severe OGD, and it can act in a paracrine manner.

We and others provide evidence that EPO protects neurons by preventing apoptosis (Digicaylioglu and Lipton, 2001; Sirén et al., 2001). We demonstrate that EPO-induced neuroprotection is EpoR-mediated. In erythropoiesis the EpoR signaling is mediated via a tyrosine phosphorylation cascade. In accordance with the functional role of JAK-2 in EpoR signaling in erythroid cells (Witthuhn et al., 1993), we found EPO-induced neuroprotection to be JAK-2-dependent. Our finding is in agreement with recent results by Digicaylioglu and Lipton (2001), who also provide strong evidence for an essential role of EpoR-mediated JAK-2 activation in neuroprotection.

The JAK-2/STAT pathway plays a key role in the anti-apoptotic signaling of EPO in hematopoiesis (Oda et al., 1998; Lawson et al., 2000). STAT1, STAT3, and STAT5 proteins have been implicated in the regulation of apoptosis (Bromberg, 2001). However, only STAT5 has been demonstrated in the anti-apoptotic signaling of EPO. In contrast to a large body of evidence on erythroid progenitors, we found no evidence for the induction of STAT5, STAT3, or STAT1 in EPO-induced neuroprotection. STATs exert their anti-apoptotic effects by the induction of $\mathrm{Bcl} 2$ family

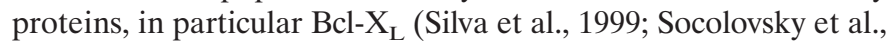
1999). We found no evidence for downstream transcriptional activation of the anti-apoptotic $B c l$ II family genes $B c l-X_{L}, B c l-2$, and Bag-1. We therefore conclude that, at least under the conditions studied here, the JAK/STAT pathway does not seem to play a significant role in EPO-induced neuroprotection.

In erythroid progenitor cells, EPO anti-apoptotic signaling is mediated by ERK, a downstream-signaling kinase of the MAPK pathway (Sui et al., 2000). ERK activation correlates with neuroprotection in a rat model of global cerebral IP (Shamloo et al., 1999). In cultured rat hippocampal neurons ERK is activated by EPO under hypoxic conditions (Sirén et al., 2001). In contrast, we found no ERK activation in cortical cerebral neurons after EPO stimulation. The reasons for this discrepancy are unclear, but different anti-apoptotic pathways in hippocampal versus cortical cerebral neurons and other model differences (dosages, timing, etc.) have to be considered.

The ability of trophic factors to promote survival has been attributed, at least in part, to PI3K and its molecular targets (for review, see Datta et al., 1999). In particular, in erythroid precursors EPO prevents apoptotic cell death via a PI3K-dependent pathway (Bao et al., 1999; Lawson et al., 2000). In our experiments a specific inhibitor of PI3K (Davies et al., 2000) partially abolished EPO-induced protection against OGD. The fact that the inhibition was only partial may be a consequence of either incomplete inhibition of PI3K by LY294002 or the involvement of additional signaling pathways in EpoR-mediated neuroprotection (see below). The concentration of LY 294002 used in our study was comparable with that used in previous studies (Fruman et al., 1998) and could not be increased without the appearance of toxic side effects (K. Ruscher, unpublished observations). In agreement with our data, Sirén et al. (2001) have demonstrated a PI3K-dependent neuroprotective effect of EPO in rat hippocampal neurons. PI3K suppresses apoptotic cell death via its downstream effector protein kinase B (PKB)/Akt. Activated Akt kinase plays a central role in suppressing apoptosis by modulating the activities of $\mathrm{Bcl} 2$ family proteins and caspase 9 . PI3K specifically induces phosphorylation at $\mathrm{Thr}^{308}$ and $\mathrm{Ser}^{473}$, which play a central role in Akt activation (Datta et al., 1999). We found EPO-induced and PI3K-mediated activation of Akt kinase activity in cultured cortical neurons. In accordance with this finding, Sirén et al. (2001) reported EPO-induced phosphorylation of Akt at $\operatorname{Ser}^{473}$ by hypoxia in hippocampal neurons. Activated Akt, in turn, can phosphorylate Bad specifically at $\operatorname{Ser}^{136}$ (del Peso et al., 1997) and thus can inactivate Bad. Phosphorylated Bad prevents apoptosis, because unphosphorylated Bad is capable of forming heterodimers with the anti-apoptotic proteins $\mathrm{Bcl}-\mathrm{X}_{\mathrm{L}}$ or Bcl-2 and thereby antagonizes their anti-apoptotic function ( $\mathrm{Z}$ ha et al., 1996). For the first time we describe a correlation between EPOinduced and PI3K-mediated phosphorylation of Bad at Ser ${ }^{136}$ and neuroprotection. Our results suggest that Bad phosphorylation plays a role in EPO-induced prevention of neuronal apoptosis, but other PKB/Akt substrates like caspase 9 (Datta et al., 1999), also have to be considered.

Surprisingly, we found that even very short pretreatment (5 min) with EPO induces significant protection against OGD in neurons. Such a rapid effect is not consistent with the induction of protective gene expression by EPO. Post-translational regulation, for example protein phosphorylation, as described above, is more likely to account for such fast cellular responses. However, because in our experiments the neuroprotective effect is not only sustained but intensified after $24 \mathrm{hr}$ of EPO exposure, the additional induction of gene expression programs seems likely. Recently, the activation of the transcription factor NF- $\kappa$ B has been reported as an essential step in EPO-induced neuroprotection (Digicaylioglu and Lipton, 2001). This pathway is JAK-2dependent but PI3K-independent and thus may explain why in our study EPO-induced neuroprotection is blocked only partially by the specific PI3-kinase inhibitor LY294002, although this com- 
pound inhibited Akt kinase completely and Bad phosphorylation nearly completely to control level. Remarkably, the activation of $\mathrm{NF}-\kappa \mathrm{B}$ is a key event for IP, as demonstrated recently in an in vivo model of global ischemia (Blondeau et al., 2001; Ravati et al., 2001).

In conclusion, our data provide evidence for a new, endogenous signaling cascade inducing tolerance against ischemia in the brain. Our results demonstrate that IP in the brain is the result of complex signaling programs involving various cellular elements of the brain. By a combination of transcriptional as well as posttranslational mechanisms the brain can protect itself against the deprivation of substrate. Understanding these mechanisms may allow us in the future to induce or boost endogenous protection in patients as a novel strategy to safeguard the brain against hypoxia/ischemia.

\section{REFERENCES}

Bao H, Jacobs-Helber SM, Lawson AE, Penta K, Wickrema A, Sawyer ST (1999) Protein kinase B (c-Akt), phosphatidylinositol 3-kinase, and STAT5 are activated by erythropoietin (EPO) in HCD57 erythroid cells but are constitutively active in an EPO-independent, apoptosisresistant subclone (HCD57-SREI cells). Blood 93:3757-3773.

Bergeron M, Gidday JM, Yu AY, Semenza GL, Ferriero DM, Sharp FR (2000) Role of hypoxia-inducible factor-1 in hypoxia-induced ischemic tolerance in neonatal rat brain. Ann Neurol 48:285-296.

Bernaudin M, Marti HH, Roussel S, Divoux D, Nouvelot A, MacKenzie ET, Petit E (1999) A potential role for erythropoietin in focal permanent cerebral ischemia in mice. J Cereb Blood Flow Metab 19:643-651.

Bernaudin M, Bellail A, Marti HH, Yvon A, Vivien D, Duchatelle I, Mackenzie ET, Petit E (2000) Neurons and astrocytes express EPO mRNA: oxygen-sensing mechanisms that involve the redox-state of the brain. Glia 30:271-278.

Blondeau N, Widmann C, Lazdunski M, Heurteaux C (2001) Activation of the nuclear factor $-\kappa \mathrm{B}$ is a key event in brain tolerance. $\mathrm{J}$ Neurosci 21:4668-4677.

Brewer GJ (1995) Serum-free B27/Neurobasal medium supports differentiated growth of neurons from the striatum, substantia nigra, septum, cerebral cortex, cerebellum, and dentate gyrus. J Neurosci Res 42:674-683

Brines ML, Ghezzi P, Keenan S, Agnello D, de Lanerolle NC, Cerami C, Itri LM, Cerami A (2000) Erythropoietin crosses the blood-brain barrier to protect against experimental brain injury. Proc Natl Acad Sci USA 97:10526-10531.

Bromberg JF (2001) Activation of STAT proteins and growth control. BioEssays 23:161-169.

Bruer U, Weih M, Isaev N, Meisel A, Ruscher K, Bergk A, Trendelenburg G, Wiegand F, Victorov I, Dirnagl U (1997). Induction of tolerance in rat cortical neurons: hypoxic preconditioning. FEBS Lett 414:117-121.

Calapai G, Marciano MC, Corica F, Allegra A, Parisi A, Frisina N, Caputi AP, Buemi M (2000) Erythropoietin protects against brain ischemic injury by inhibition of nitric oxide formation. Eur J Pharmacol 401:349-356.

Chomczynski P, Sacchi N (1987) Single-step method of RNA isolation by acid guanidinium thiocyanate-phenol-chloroform extraction. Anal Biochem 162:156-159.

Constantinescu SN, Huang LJ, Nam H, Lodish HF (2001) The erythropoietin receptor cytosolic juxtamembrane domain contains an essential, precisely oriented, hydrophobic motif. Mol Cell 7:377-385.

Datta SR, Brunet A, Greenberg ME (1999) Cellular survival: a play in three Akts. Genes Dev 13:2905-2927.

Davies SP, Reddy H, Caivano M, Cohen P (2000) Specificity and mechanism of action of some commonly used protein kinase inhibitors. Biochem J 351:95-105.

del Peso L, Gonzalez-Garcia M, Page C, Herrera R, Nunez G (1997) Interleukin-3-induced phosphorylation of BAD through the protein kinase Akt. Science 278:687-689.

Digicaylioglu M, Lipton SA (2001) Erythropoietin-mediated neuroprotection involves cross-talk between $\mathrm{Jak} 2$ and NF- $\kappa \mathrm{B}$ signaling cascades. Nature 412:641-647.

Digicaylioglu M, Bichet S, Marti HH, Wenger RH, Rivas LA, Bauer C, Gassmann M (1995) Localization of specific erythropoietin binding sites in defined areas of the mouse brain. Proc Natl Acad Sci USA 92:3717-3720.

Fruman DA, Meyers RE, Cantley LC (1998) Phosphoinositide kinases. Annu Rev Biochem 67:481-507.

Furuya K, Ginis I, Takeda H, Chen Y, Hallenbeck JM (2001) Cellpermeable exogenous ceramide reduces infarct size in spontaneously hypertensive rats supporting in vitro studies that have implicated ceramide in induction of tolerance in ischemia. J Cereb Blood Flow Metab $21: 226-232$.

Gonzalez-Zulueta M, Feldman AB, Klesse LJ, Kalb RG, Dillman JF, Parada LF, Dawson TM, Dawson VL (2000) Requirement for nitric

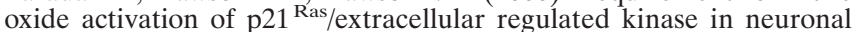
ischemic preconditioning. Proc Natl Acad Sci USA 97:436-441.

Grabb MC, Choi DW (1999) Ischemic tolerance in murine cortical cell culture: critical role for NMDA receptors. J Neurosci 19:1657-1662.

Grad JM, Zeng XR, Boise LH (2000) Regulation of Bcl-X $\mathrm{I}_{\mathrm{L}}$ : a little bit of this and a little bit of STAT. Curr Opin Oncol 12:543-549.

Herlaar E, Brown Z (1999) p38 MAPK signaling cascades in inflammatory disease. Mol Med Today 5:439-447.

Heurteaux C, Lauritzen I, Widmann C, Lazdunski M (1995) Essential role of adenosine, adenosine A1 receptors, and ATP-sensitive $\mathrm{K}^{+}$ channels in cerebral ischemic preconditioning. Proc Natl Acad Sci USA 92:4666-4670.

Juul SE, Anderson DK, Li Y, Christensen RD (1998) Erythropoietin and erythropoietin receptor in the developing human central nervous system. Pediatr Res 43:40-49.

Kitagawa K, Matsumoto M, Tagaya M, Hata R, Ueda H, Niinobe M, Handa N, Fukunaga R, Kimura K, Mikoshiba K, Kamada T (1990) "Ischemic tolerance" phenomenon found in the brain. Brain Res 528:21-24.

Koh JY, Choi DW (1987) Quantitative determination of glutamatemediated cortical neuronal injury in cell culture by lactate dehydrogenase efflux assay. J Neurosci Methods 20:83-90.

Konishi Y, Chui DH, Hirose H, Kunishita T, Tabira T (1993) Trophic effect of erythropoietin and other hematopoietic factors on central cholinergic neurons in vitro and in vivo. Brain Res 609:29-35.

Lawson AE, Bao H, Wickrema A, Jacobs-Helber SM, Sawyer ST (2000) Phosphatase inhibition promotes anti-apoptotic but not proliferative signaling pathways in erythropoietin-dependent HCD57 cells. Blood 96:2084-2092

Liu C, Shen K, Liu Z, Noguchi CT (1997) Regulated human erythropoietin receptor expression in mouse brain. J Biol Chem 272:32395-32400.

Liu J, Ginis I, Spatz M, Hallenbeck JM (2000) Hypoxic preconditioning protects cultured neurons against hypoxic stress via TNF- $\alpha$ and ceramide. Am J Physiol Cell Physiol 278:C144-C153.

Marti HH, Wenger RH, Rivas LA, Straumann U, Digicaylioglu M, Henn V, Yonekawa Y, Bauer C, Gassmann M (1996) Erythropoietin gene expression in human, monkey, and murine brain. Eur J Neurosci 8:666-676.

Marti HH, Gassmann M, Wenger RH, Kvietikova I, Morganti-Kossmann MC, Kossmann T, Trentz O, Bauer C (1997) Detection of erythropoietin in human liquor: intrinsic erythropoietin production in the brain. Kidney Int 51:416-418.

Masuda S, Nagao M, Takahata K, Konishi Y, Gallyas Jr F, Tabira T, Sasaki R (1993) Functional erythropoietin receptor of the cells with neural characteristics. Comparison with receptor properties of erythroid cells. J Biol Chem 268:11208-11216.

Masuda S, Okano M, Yamagishi K, Nagao M, Ueda M, Sasaki R (1994) A novel site of erythropoietin production. Oxygen-dependent production in cultured rat astrocytes. J Biol Chem 269:19488-19493.

McCarthy KD, de Vellis J (1980) Preparation of separate astroglial and oligodendroglial cell cultures from rat cerebral tissue. J Cell Biol 85:890-902.

Moncayo J, de Freitas GR, Bogousslavsky J, Altieri M, van Melle G (2000) Do transient ischemic attacks have a neuroprotective effect? Neurology 54:2089-2094.

Morishita E, Masuda S, Nagao M, Yasuda Y, Sasaki R (1997) Erythropoietin receptor is expressed in rat hippocampal and cerebral cortical neurons, and erythropoietin prevents in vitro glutamate-induced neuronal death. Neuroscience 76:105-116.

Murata S, Usuda N, Okano A, Kobayashi S, Suzuki T (2000) Occurrence of a transcription factor, signal transducer and activators of transcription 3 (STAT3) in the postsynaptic density of the rat brain. Brain Res Mol Brain Res 78:80-90.

Oda A, Sawada K, Druker BJ, Ozaki K, Takano H, Koizumi K, Fukada Y, Handa M, Koike T, Ikeda Y (1998) Erythropoietin induces tyrosine phosphorylation of Jak2, STAT5A, and STAT5B in primary cultured human erythroid precursors. Blood 92:443-451.

Perez-Pinzon MA, Xu GP, Dietrich WD, Rosenthal M, Sick TJ (1997) Rapid preconditioning protects rats against ischemic neuronal damage after 3 , but not 7 , days of reperfusion following global cerebral ischemia. J Cereb Blood Flow Metab 17:175-182.

Plamondon H, Blondeau N, Heurteaux C, Lazdunski M (1999) Mutually protective actions of kainic acid epileptic preconditioning and sublethal global ischemia on hippocampal neuronal death: involvement of adenosine A1 receptors and $\mathrm{K}_{\mathrm{ATP}}$ channels. J Cereb Blood Flow Metab 19:1296-1308.

Prass K, Ruscher K, Karsch M, Isaev N, Megow D, Priller J, Scharff A, Dirnagl U, Meisel A (2002) Desferrioxamine induces delayed tolerance against cerebral ischemia in vivo and in vitro. J Cereb Blood Flow Metab 22:520-525. 
Ravati A, Ahlemeyer B, Becker A, Klumpp S, Krieglstein J (2001) Preconditioning-induced neuroprotection is mediated by reactive oxygen species and activation of the transcription factor nuclear factor- $\kappa \mathrm{B}$. J Neurochem 78:909-919.

Ridet JL, Malhotra SK, Privat A, Gage FH (1997) Reactive astrocytes: cellular and molecular cues to biological function. Trends Neurosci 20:570-577.

Ruscher K, Isaev N, Trendelenburg G, Weih M, Iurato L, Meisel A, Dirnagl U (1998) Induction of hypoxia-inducible factor 1 by oxygen glucose deprivation is attenuated by hypoxic preconditioning in rat cultured neurons. Neurosci Lett 254:117-120.

Ruscher K, Reuter M, Kupper D, Trendelenburg G, Dirnagl U, Meisel A (2000) A fluorescence-based nonradioactive electrophoretic mobility shift assay. J Biotechnol 78:163-170.

Sadamoto Y, Igase K, Sakanaka M, Sato K, Otsuka H, Sakaki S, Masuda S, Sasaki R (1998) Erythropoietin prevents place navigation disability and cortical infarction in rats with permanent occlusion of the middle cerebral artery. Biochem Biophys Res Commun 253:26-32.

Sakanaka M, Wen TC, Matsuda S, Masuda S, Morishita E, Nagao M, Sasaki R (1998) In vivo evidence that erythropoietin protects neurons from ischemic damage. Proc Natl Acad Sci USA 95:4635-4640.

Semenza GL (2000) HIF-1: mediator of physiological and pathophysiological responses to hypoxia. J Appl Physiol 88:1474-1480.

Shamloo M, Rytter A, Wieloch T (1999) Activation of the extracellular signal-regulated protein kinase cascade in the hippocampal CA1 region in a rat model of global cerebral ischemic preconditioning. Neuroscience 93:81-88

Silva M, Benito A, Sanz C, Prosper F, Ekhterae D, Nunez G, FernandezLuna JL (1999) Erythropoietin can induce the expression of Bcl-X through STAT5 in erythropoietin-dependent progenitor cell lines. J Biol Chem 274:22165-22169.

Sinor AD, Greenberg DA (2000) Erythropoietin protects cultured cortical neurons, but not astroglia, from hypoxia and AMPA toxicity. Neurosci Lett 290:213-215.

Sirén AL, Fratelli M, Brines M, Goemans C, Casagrande S, Lewczuk P,
Keenan S, Gleiter C, Pasquali C, Capobianco A, Mennini T, Heumann R, Cerami A, Ehrenreich H, Ghezzi P (2001) Erythropoietin prevents neuronal apoptosis after cerebral ischemia and metabolic stress. Proc Natl Acad Sci USA 98:4044-4049.

Socolovsky M, Fallon AE, Wang S, Brugnara C, Lodish HF (1999) Fetal anemia and apoptosis of red cell progenitors in STAT5 $\mathrm{a}^{-1-} / 5 \mathrm{~b}^{-1-}$ mice: a direct role for STAT5 in Bcl-X $\mathrm{L}_{\mathrm{L}}$ induction. Cell 98:181-191.

Sui X, Krantz SB, Zhao ZJ (2000) Stem cell factor and erythropoietin inhibit apoptosis of human erythroid progenitor cells through different signaling pathways. Br J Haematol 110:63-70.

Wang X, Li X, Erhardt JA, Barone FC, Feuerstein GZ (2000) Detection of tumor necrosis factor- $\alpha$ mRNA induction in ischemic brain tolerance by means of real-time polymerase chain reaction. J Cereb Blood Flow Metab 20:15-20.

Weih M, Harms L, Dirnagl U, Kallenberg K, Einhaupl KM (1999) Attenuated stroke severity after prodromal TIA: a role for ischemic tolerance in the brain? Stroke 30:1851-1854.

Witthuhn BA, Quelle FW, Silvennoinen O, Yi T, Tang B, Miura O, Ihle JN (1993) JAK2 associates with the erythropoietin receptor and is tyrosine phosphorylated and activated following stimulation with erythropoietin. Cell 74:227-236.

Yamaguchi A, Tamatani M, Matsuzaki H, Namikawa K, Kiyama H, Vitek MP, Mitsuda N, Tohyama M (2001) Akt activation protects hippocampal neurons from apoptosis by inhibiting transcriptional activity of p53. J Biol Chem 276:5256-5264.

Zaman K, Ryu H, Hall D, O’Donovan K, Lin KI, Miller MP, Marquis JC, Baraban JM, Semenza GL, Ratan RR (1999) Protection from oxidative stress-induced apoptosis in cortical neuronal cultures by iron chelators is associated with enhanced DNA binding of hypoxia-inducible factor-1 and ATF-1/CREB and increased expression of glycolytic enzymes, p21 waf1/cip1, and erythropoietin. J Neurosci 19:9821-9830.

Zha J, Harada H, Yang E, Jockel J, Korsmeyer SJ (1996) Serine phosphorylation of death agonist BAD in response to survival factor results in binding to 14-3-3, not Bcl- $\mathrm{X}_{\mathrm{L}}$. Cell 87:619-628. 